Gordon, B., (2020). An alternative conceptualization of the Teaching Personal and Social Responsibility model. Journal of Physical Education, Recreation \& Dance.91(7), 9-14.

Barrie Gordon $\mathrm{PhD}$

Faculty of Education

Victoria University of Wellington

New Zealand

barrie.gordon@vuw.ac.nz 


\section{An alternative conceptualization of the Teaching Personal and Social Responsibility model.}

The Teaching Personal and Social Responsibility model (TPSR) is a well-established pedagogical approach that is implemented in physical education and sport-based youth development programs in the USA and internationally. At the center of the model are the five goals/levels which describe the core values of TPSR. These are traditionally presented as five cumulative levels with transfer of learning being designated as level five. This article offers an alternative model which presents the levels/goals as non- hierarchical and positions transfer of learning, not as the final level of a cumulative process, but as fundamental to the model and underpinning the other four levels/goals. The article concludes with suggestions on how teachers and coaches can implement this alternative conceptualized model into their practice.

Keywords: transfer of learning; Teaching Personal and Social Responsibility model; physical education; sport-based youth development 
The Teaching Personal and Social Responsibility model (TPSR) is a well-established pedagogical approach that is implemented in physical education and sport based youth development programs in the USA and internationally (Coulson, Irwin, \& Wright, 2013; Hellison, 2011; Lee \& Choi, 2015; Walsh, Veri, \& Willard, 2015; Wright, Jacobs, Ressler, \& Jung, 2016). Developed by Don Hellison it is essentially a value based approach to teaching and coaching that has the twin goals of facilitating the learning of values or life skills while simultaneously meeting the more traditional outcomes associated with sport or physical education (Hellison, 2011). While acknowledging the need to meet both goals Hellison (2011) emphasized that:

... the core value of TPSR is 'putting kids first' and being youth centred ... It is not putting physical activity or an active lifestyle or sport or fitness first, and it's certainly not putting oneself first (as in focussing on one's win-loss record) but what is it .... it's simply to help kids become better people. That includes promoting human decency and positive relationships with others. (p.18)

The following description of the model is by necessity a very brief overview and it is suggested that readers wishing to gain a more in-depth understanding of TPSR can do so in the first instance through reading Teaching Personal and Social Responsibility Through Physical Education (Hellison, 2011) or via the TPSR Alliance website.

Underpinning the model are five program leader responsibilities, or themes, which Hellison felt needed to be a constant presence in any authentic implementation of TPSR. These responsibilities are: the gradual empowerment of participants; ensuring opportunities for self-reflection; embedding TPSR into the physical activities; facilitating transfer of learning to other areas of participants lives; and being relational in a positive and supportive way. For teachers and leaders implementing the model there is a suggested format for taking 
sessions. This consists of an initial relational time with participants, an awareness talk around the values, the activity session, a group discussion and then time for personal reflection.

At the center of the model are the five goals/levels which describe the core values of TPSR. These are traditionally presented as cumulative levels, Level 1 Respect; Level II Effort; Level III Self-direction; Level IV Caring/Leadership and Level V Transfer of Learning (Hellison, 2011; Hellison et al., 2000). Within a physical education class, for example, a student demonstrates respect by behaving in a manner that does not interfere with other student's right to learn, or the teacher's right to teach, in a psychologically and physically safe environment. Effort/Participation is demonstrated by students being involved and participating in the program, being willing to make an effort when things get tough and be willing to try new things. Self-direction is designed to extend students from participation to beginning to take personal responsibility for their learning and wellbeing. This goal includes demonstrating the ability to set and work toward personal goals. The fourth level caring/leadership is intended to help students develop empathy toward others and is demonstrated by their willingness to help others when needed. Transfer of learning (TOL) is the final level and refers to the application of the learning of the other four goals in contexts outside of the program. This could include school, home, work or in their community in general. TOL is the most difficult level to observe as it occurs away from the TPSR context. In some cases, a Level zero is also identified. Level zero is not a goal or value but is simply a description of behaviors that are unaligned with any of the values.

The presentation of the levels/goals as a series of cumulative levels is ubiquitous in practical contexts, where the levels are often displayed as cumulative on posters, in text books (Hellison, 2011; Metzler, 2000) and in TPSR related research studies (Hemphill, Templin, \& Wright, 2013; Pan \& Keh, 2014). This article offers an alternative model (Figure 1) which presents the levels/goals as non- hierarchical and positions TOL, not as the final 
level of a cumulative process, but as fundamental to the model and underpinning the other four levels/goals.

\section{Advantages of labeling the values as cumulative levels}

The presentation of the five goals as hierarchical levels has survived the test of time and the frameworks longevity suggests that there are advantages to this approach and that many practitioners find it successful. For those new to TPSR there is a feeling of structure and certainty around a sequence of steps or levels. TPSR is by essence a less structured way of teaching than traditional approaches and the sequence of five levels offers some degree of certainty. There is also the feeling that the values can be introduced and taught more easily in discrete blocks, one at a time, which is appealing for teachers and coaches who can potentially feel overwhelmed when faced with introducing the whole model at once. This is also important for the students/participants who may see the structured sequence as more achievable than if introduced to all five goals/levels at once. Hellison (2011) considered the realities of physical education teaching when he wrote 'However it [cumulative levels] remains a popular choice for many program leaders, especially PE teachers who have large classes and see many students each day ... By necessity it becomes TPSR lite' (p. 35). A further advantage is that the long history of cumulative levels has created a shared understanding among those using the model. This common understanding gives a sense of belonging and shared knowledge which helps maintain a sense of a TPSR community and helps facilitate discussions amongst TPSR practitioners and academics.

\section{Disadvantages of labelling the values as levels}

It is worth noting that the presentation of the levels/values as cumulative has not been universally supported and has been critiqued by a number of writers. Shield and Bredemeier (1995) expressed doubts about the way that the goals were presented as developmental levels, as a series of progressive stages to be climbed as the students advanced morally. They 
believed that conceptualising the levels "as simultaneously operating components of responsible behaviour" (p. 208), rather than a "quasi-developmental progression" (p. 207) would make the model stronger. They noted that while the intent of TPSR was not

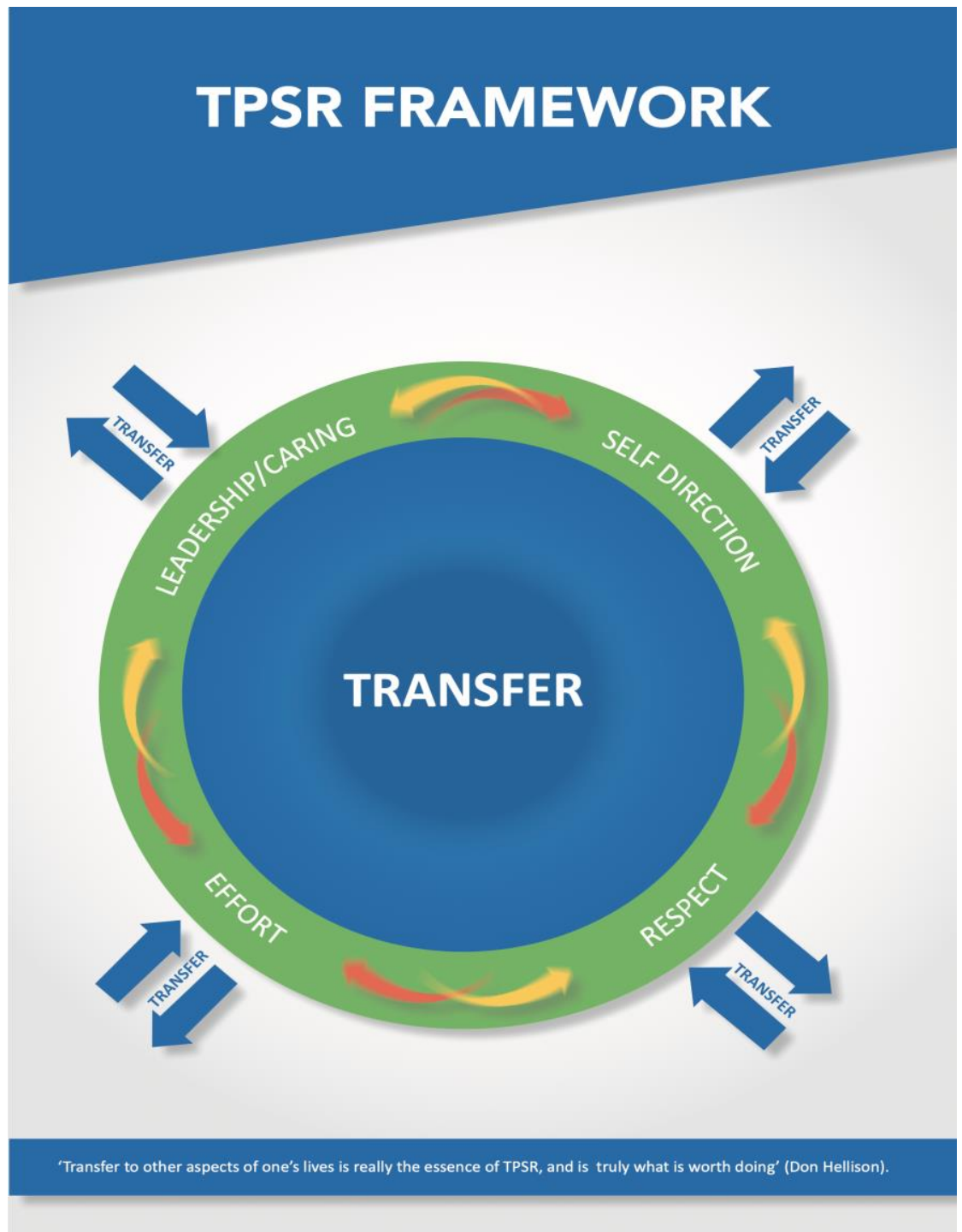

Figure 1: Alternative conceptualization of the Teaching Personal and Social Responsibility model.

necessarily to present the levels as cumulative, the reality was that this is what occurred in practice. They observed that students can work at a range of levels over any period of time: "It may be that a person is caring (Level IV), self-directed (Level III), and involved (Level II), but she loses her temper (Level I) on one day and fails in a different component on 
another day" (p. 209). They further suggested that, if it was necessary to have the levels presented as cumulative levels, they could, in fact, "be arranged in any number of ways with, for example, caring (Level IV) being placed between respect (Level I) and effort (Level II)" (p. 209).

Hellison himself was not fully convinced on the merits of presenting the goals/values cumulatively. While this was his initial approach, when he was developing TPSR, he commented that "as I dug deeper into each of the levels and began to appreciate their nuances, it seemed best, at least in my situation, to treat each separately as a loose progression" (Hellison, 2011; p. 35). This decision was partly driven by his understanding that in the messy reality of practice, things were not as ordered as the five-level framework suggested. He also identified that kids can operate at many different levels in a single session and that "some kids have great difficulty working alone but are competent leaders. Others have major temper issues, but when they manage to be temporarily under control, they are model students" (p.35).

His position, however, seems equivocal in that he understood the reality of practice for many teachers and leaders was different to his own work and he offered support for their position in his writings:

Taking on the five levels at once is asking a lot of students. One way to address this issue is to present the responsibilities as a loose progressions of levels ... Such a teaching-learning progression can help the teacher plan each lesson as well as individualise the programme. (Hellison, 2000, p. 40).

The labeling of the values as levels one to five suggests a hierarchy where a level must be 'achieved' before the next can be attempted. Participants and teachers/coaches can come to believe, for example, that making an effort should wait until they have demonstrating respect, or that caring/leadership should be addressed only after the previous 
three levels have been reached. This way of looking at the values can lead to lost opportunities and restrict the development that occurs for participants. A teacher who notices a student making a good effort in class should take the opportunity to discuss the value of applying greater effort in other classes or at home [transfer] at that moment rather than leaving it for a later date when they have 'achieved' the other goals/values.

This scenario illustrates a major concern of the cumulative levels approach which has TOL designated as level five, the last value to be considered. Placing TOL at level five gives the message that using the values in contexts outside of the physical education class is something to be considered when all the other levels have been met. This can lead to teachers and leaders feeling that transfer is not a prime area of emphasis, which in turn lowers the chances of students transferring the values into other areas of their lives. This is unfortunate as transfer is essentially the fundamental reason for TPSR being taught. As Hellison (2011) wrote 'transfer is really my ultimate goal in teaching kids to take personal and social responsibility’ (p. 25).

How then is transfer addressed in the reality of TPSR practice? Gordon (2010) found that transfer was considered a 'nice to have' outcome rather than a fundamental aspect of the model while Mrugala (2002) found teachers were more concerned with the impact of TPSR on classroom behavior than transfer. Escarti, Llopis-Goig, \& Wright (2017) study of a school wide implementation of the model found that despite receiving extensive professional development on the model 'there was no systematic focus on the promotion of transfer in this study' (p. 20) by the teachers. The authors in considering this outcome concluded that 'the lack of focus on the transfer may be connected to the fact that teachers were directed to progress through the levels sequentially' (p. 21).

While the positioning of transfer at the fifth level of a hierarchal sequence of levels cannot be considered the only reason for the lack of emphasis on transfer it is reasonable to 
consider that it is an important contributing factor. Hellison (2011) acknowledged this when in describing the disadvantages of the cumulative approach he commented that 'most cumulative levels users completely ignore level V [Transfer] (p. 35).

\section{Alternative conceptualization of the TPSR model}

An alternative way to consider the levels/goals is that presented in Figure one. In this model there are two main differences in emphasis. The first is that the values/goals are presented as independent, rather than cumulative and the second is in the prioritizing of transfer of learning.

In the alternative model the values/goals are presented as non-hieratical, as independent but related in a way that gives flexibility to the teachers and leaders in how and when they are presented. They are positioned to indicate that there are no values 'higher' than the others and arrows are included to indicate that they can be moved to alternative positions if required. This flexibility allows the values/goals to be addressed in any order and if appropriate more than one goal/value can be considered in any single session.

The second major difference is that TOL is positioned as central to the model and as underpinning the four goals/values. This is a significant change to how transfer of learning is traditionally presented in TPSR and is intended to emphasis its philosophical and practical importance. Transfer of learning is a topic of interest to many academics involved with TPSR (Conceled reference, ; Jacobs \& Wright, 2018; Martinek, Schilling, \& Johnson, 2001) and in the wider field of positive youth development (Durlak, Weissberg, Dymnicki, Taylor, \& Schellinger, 2011). This interest is largely based on an understanding that the impact of participation outside of the context of the program is in many ways the most important measure of a program's success.

Transfer of learning is often presented as a one-dimensional process where learning that occurs within the program is applied by participants in other areas of their lives. In the 
conceptualized model (Figure 1) presented in this article transfer is shown as being two dimensional with the introduction of a second transfer direction, transfer from outside back into the program. Transfer in this second direction acknowledges the impact of what happens outside of the programme on the behavior and learning that occurs within the programme. Events and experiences that occur for TPSR participants away from the program have the potential to both support and undermine the TPSR related learning. A student who is considering the applicability of their learning around the benefits of increased effort in class may have that strongly reinforced by comments from a family member about their effort helping around the home. This reinforcement can be transferred back into the TPSR programme leading to increased engagement, learning and understanding. Alternatively, the learning and commitment could be undermined if a participant was to make an obvious effort in another class and was teased for it by his peers. It is important that when discussion around transfer occur within TPSR programs both directions be addressed.

\section{Planning for Transfer}

There are many practitioners who believe that exposure to values is sufficient and that if this occurs transfer to other areas of participants lives will naturally follow. Gordon and Doyle (2015) described this as:

... the Bo-Peep theory of teaching for TOL. In this depiction TOL takes care of itself: "Leave them alone and they'll come home wagging their tails behind them." This is the tacit theory of TOL and it is ubiquitous. TPSR educators join others in assuming that providing students are introduced to values, concepts and skills, and have had opportunities to apply them then TOL is sure to follow. (p. 156) 
While this approach is common Hellison (2011) joined many others in identifying that if teachers and coaches wanted kids to use their learning in other areas of their lives this would only occur if there was a specific focus on transfer:

Kids can learn to take responsibility in PE and PA programs, but transferring these behaviors from the activity setting to other arenas of life such as other places in school, the playground, the street (if possible) and home is not automatic. It must be taught just as surely as respect for others must be taught. (p.25)

A conscious effort to include planning for transfer is therefore important. This is especially the case where transfer has not previously been an area of emphasis for teachers and leaders. While this may appear challenging at first there are a number of actions that can be taken by a teacher or coach that will increase the likelihood of it occurring (Gordon \& Doyle, 2015).

\section{Facilitating Transfer in practice: Suggestions for teachers and coaches}

The repositioning of transfer into the center of the model offers teachers and coaches both opportunities and challenges around how they will address transfer in their practice. Rather than being the last value to be considered, as is often the case with a cumulative levels approach, transfer needs to be considered from day one and throughout the program (Walsh, Ozaeta, \& Wright, 2010). This requires a change in focus for teachers /coaches who may have previously given little consideration to teaching around transfer.

For coaches and teachers who decide that it is important to address transfer, the challenge is how to do so effectively, without causing themselves, of their kids, undue stress. One of the strengths of the TPSR model is its flexibility in meeting the needs of a range of diverse learners. Its focus on relationships, and meeting the needs of all learners, means that teachers 
and coaches are expected to modify their approach to best meet the participants needs rather than expect participants to make the adjustments. The following ideas are suggestions offered as a starting point for teachers and coaches that may or may not be suitable for the children in front of you. The language, for example, may need to be changed to ensure full comprehension and engagement.

- Introduce transfer at the start of the program and continue to refer to it throughout. When introducing the TPSR model a simple comment along the lines of 'what we are learning in this program can also be useful for you at school and other parts of your life' will establish that transfer is an important part of the program.

- Plan and systematically monitor that you mention the impact of their learning on other areas of their lives at least once every class or training session.

- Consider incorporating transfer into the awareness talk, group discussion or personal reflection segments in the program. This does not need to be extensive and can simply be at a level that positions transfer as an integral part of the program. In the awareness talk, for example, when mentioning effort and the importance of trying out and persisting at new experiences the coach or teacher could simply add 'so apart from it being important to try new things here in our program where else could it be important? When asking participants to reflect on whether they had helped someone in class without being asked [caring], the addition of "how about since we last met, have you helped someone without being asked at home, or in other classes" adds the dimension of transfer in an effective and relatively simple way. This can be extended to "over the next week see if any opportunities for you to help someone without being asked happen. We will talk about it next week".

- The likelihood of transfer occurring will be increased if the teacher/coach can “identify authentic opportunities for participants to use their learning in their lives and 
for participants to be suitably prepared, and have the personal capacity, to take advantage of these opportunities when they arose" (Gordon \& Doyle, 2013, p.158). During discussions, it will be helpful if these issues are specifically addressed. "you have shown you can make a great effort in PE, do you think you can make the same effort in math. What would help you make the effort"?

- It is also important to emphasis the personal benefits to participants if they make the change 'so what do you think would happen if you did make a big effort in math, what would be the benefits for you'?

- Transfer has been identified as a two-way process where what occurs outside the program can have an impact on the teaching and learning that occurs within sessions. This is another issue that teachers and coaches should plan to address "I know many of you are going to try and make an extra effort in math, how do you think your friends will react? Is it possible they might tease you about it? What would be a good response if they did"? The identifying of potential problems to achieving TOL, and addressing them through the program, can be an important step in helping facilitate TOL.

\section{Discussion}

It is the intention of this article to offer an alternative way of thinking about teaching and coaching with TPSR that, hopefully, will resonate with practitioners and academics. It is done while acknowledging that the cumulative level model has a long history and has been successfully implemented over many years. The author considers, however, that the removal of cumulative levels and the repositioning of transfer as fundamental to implementations of TPSR is more closely aligned to Don Hellison's philosophy and intent for the model. The importance given to transfer is not unique to TPSR but is also aligned to the wider field of 
sport based youth development and positive youth development (Danish, Forneris, Hodge, \& Heke, 2004; Fraser-Thomas, Cote, \& Deakin, 2005; Gould \& Carson, 2008).

For teachers and coaches who choose to use Figure 1 as their conceptual framework, there will be implications for the way that they introduce and embed the model into their practice. They will first need to consider how they introduce and teach the four values. Will they be introduced one at a time and if so in what order? The removal of the hierarchal level's framework offers an opportunity for teachers and coaches to tease out the interrelationships between the values in a more nuanced way. This allows participants to understand the values more holistically and to gain a sense of them being part of an integrated whole rather than as being separate and individual. How then can teachers and coaches best facilitate this deeper understanding?

The repositioning of transfer also challenges teachers and coaches to consider the degree to which they are willing to commit to ensuring that teaching and facilitating TOL is genuinely embedded in the program. Hellison (2011) identified the importance transfer held for him when he wrote:

I had to build it into my goals or else leave it to chance. All along my sense of purpose, my vision, my passion has been to help kids lead better lives. But their lives don't end when they leave the gym. (p. 25)

While the two frameworks have been presented as binary, it is suspected that in the pragmatic realities of practice, teachers and leaders address the values in a variety of ways. While some may adhere strictly to cumulative levels, others may be less structured in their approach and present the values in a manner that is more in alignment with the model suggested in this article. There will also be a range of commitment to facilitating TOL among teachers and coaches. Whatever the reality is of teachers and coaches' practice, it is hoped that the 
alternative framework offered in this article, will encourage teachers and coaches using TPSR to examine the ways in which they implement the model and consider whether they wish to make changes in their practice.

\section{References}

Coulson, C., Irwin, C., \& Wright, P. (2013). Applying Hellison's responsibility model in a youth residential treatment facility: a practical inquiry project. Agora, 14(1), 38-54.

Danish, S., Forneris, T., Hodge, K., \& Heke, I. (2004). Enhancing youth development through sport. World Leisure Journal, 46(3), 38-49.

Durlak, J. A., Weissberg, R. P., Dymnicki, A. B., Taylor, R. D., \& Schellinger, K. B. (2011). The impact of enhancing students' social and emotional learning: A meta-analysis of school-based universal interventions. Child development, 82(1), 405-432.

Escartí, A., Llopis-Goig, R., \& Wright, P. (2017). Assessing the implementation fidelity of a school-based teaching personal and social responsibility program in physical education and other subject areas. Journal of Teaching in Physical Education, 37(1), $12-23$.

Fraser-Thomas, J., Cote, J., \& Deakin, J. (2005). Youth sport programs: An avenue to foster postive youth development. Physical Education and Sport Pedagogy, 10(1), 19-40.

Gordon, B. (2010). An examination of the Responsibility Model in a New Zealand secondary school physical education programme. The Journal of Teaching in Physical Education. 29 (1) 21-37

Gordon, B. \& Doyle, S. (2015). Teaching personal and social responsibility and the transfer of learning: Opportunities and challenges for teachers and coaches. Journal of Teaching in Physical Education.34, 152-161. 
Gould, D., \& Carson, S. (2008). Life skills development through sport: Current status and further directions. International Review of Sport and Exercise Psychology, 1(1), 5868.

Hellison, D. (2011). Teaching personal and social responsibilty through physical education (3rd ed.). Champaign:IL: Human Kinetics.

Hellison, D., Cutforth, N., Kallusky, J., Martinek, T., Parker, M., \& Stiehi, J. (2000). Youth development and physical activity. Champaign, IL: Human Kinetics.

Hemphill, M., Templin, T., \& Wright, P. (2013). Implementation and outcomes of a responsibility-based continuing professional development protocol in physical education. Sport, Education and Society. doi: 10.1080/13573322.2012.761966 Jacobs, J., \& Wright, P. (2018). Transfer of life skills in sport-based youth development programs: A conceptual framework bridging learning to application. Quest, 70(1), 8199. doi: $10.1080 / 00336297.2017 .1348304$

Lee, \& Choi, E. (2015). The influence of professional development on teachers implementation of the Teaching Personal and Social Responsibility model. Journal of Teaching in Physical Education, 34(4).

Martinek, T., Schilling, T., \& Johnson, D. (2001). Transferring personal and social responsibility of underserved youth to the classroom. The Urban Review, 33(1), 2945.

Metzler, M. (2000). Instructual Models for Physical Education. Needham Heights, MA: Pearson Education.

Mrugala, K. (2002). Exploratory study of responsibility model practitioners. Unpublished doctoral dissertation, University of Illinois at Chicago. 
Pan, Y.-H., \& Keh, N.-C. (2014). Teaching responsibility through physical education: Research and applications in Taiwan. Japanese Journal of Sport Education Studies, 34(1), 6369.

Shields, D., \& Bredemeier, B. (1995). Character development and physical activity. Champaign, IL: Human Kinetics.

Walsh, D., Ozaeta, J., \& Wright, P. (2010). Transference of responsibility goals to the school environment: Exploring the impact of a coaching club program. Physical Education and Sport Pedagogy, 15(1), 15-28.

Walsh, D., Veri, M., \& Willard, J. (2015). Kinesiology career club: Undergraduate student mentors' perspectives on a physical activity-based Teaching Personal and Social Responsibility program. Physical Educator, 72(2), 3017.

Wright, P., Jacobs, J., Ressler, J., \& Jung, J. (2016). Teaching for transformative educational experience in a sport for development program. Sport, Education and Society, 21(4), 531-548. 